\title{
Expression and role of interleukin-1 $\beta$ and associated biomarkers in deep vein thrombosis
}

\author{
ROUZIMAIMAITI ZILA PAI ${ }^{1}$, QINGBO FANG ${ }^{2}$, GUANGLEI TIAN ${ }^{3}$, BING ZHU $^{2}$ and XIAOHU GE ${ }^{2}$ \\ Departments of ${ }^{1}$ General Practice and ${ }^{2}$ Vascular Surgery, People's Hospital of Xinjiang Uygur Autonomous Region; \\ ${ }^{3}$ Department of Hepatobiliary Surgery, Graduate School, Xinjiang Medical University, \\ Urumqi, Xinjiang Uygur Autonomous Region 830001, P.R. China
}

Received May 7, 2019; Accepted May 5, 2021

DOI: $10.3892 /$ etm.2021.10800

\begin{abstract}
Lower extremity deep vein thrombosis (DVT) is a common peripheral vascular disease, in which inflammation plays an important role. The aim of the present study was to investigate the expression and role of inflammatory factors in DVT. A rat model of venous thrombosis of the lower extremities was established through venous ligation surgery. The rats were examined at 2, 8, 24, 48 and $72 \mathrm{~h}$ after the induction of inferior venous stenosis and compared with control and sham surgery groups. The serum levels of interleukin- $1 \beta$ (IL-1 $\beta$ ), tissue factor (TF) and xanthine oxidase (XOD) were measured using ELISAs. The morphology of the DVT tissue was observed by hematoxylin and eosin staining. Circulating endothelial cells (CECs) in peripheral blood were counted by flow cytometry. Reverse transcription-quantitative PCR and western blotting were used to detect mRNA and protein expression, respectively. The serum levels of IL- $1 \beta$, TF and XOD exhibited no significant differences between the control and sham surgery groups. However, those in the rat model of DVT presented an upward trend from 2 to $24 \mathrm{~h}$ and peaked at $24 \mathrm{~h}$, with a significant difference from the respective levels in the control and sham surgery groups. The histopathological analysis revealed the presence of red and mixed thrombi in the rats 2-48 $\mathrm{h}$ following the induction of inferior venous stenosis group with inflammatory cell infiltration in the vascular wall. Thrombus formation was evident after $72 \mathrm{~h}$. While significant difference was observed in the number of CECs in the peripheral blood between the control and sham surgery
\end{abstract}

Correspondence to: Dr Xiaohu Ge, Department of Vascular Surgery, People's Hospital of Xinjiang Uygur Autonomous Region, 91 Tianchi Road, Tianshan, Urumqi, Xinjiang Uygur Autonomous Region 830001, P.R. China

E-mail: gexiaohu_xj@163.com; 545338929@qq.com

Abbreviations: DVT, deep vein thrombosis; IL-1 $\beta$, interleukin-1 $\beta$; $\mathrm{TF}$, tissue factor; XOD, xanthine oxidase; HX, hypoxanthine; $\mathrm{XD}$, xanthine dehydrogenase

Key words: deep vein thrombosis, interleukin-1 $\beta$, xanthine oxidase, tissue factor, organizational observation, CD31 groups, the number of peripheral blood CECs in the rats with inferior venous stenosis group increased from 8 to $72 \mathrm{~h}$, with significant differences among these groups. The mRNA levels of $I L-1 \beta, T F, X O D$ and $N F-\kappa B$ in the tissues peaked at $24 \mathrm{~h}$, with significant differences compared with those in the control and sham surgery groups. In addition, the protein expression level of NF- $\mathrm{B}$ increased from 2 to $72 \mathrm{~h}$. In conclusion, these results suggest that the high expression of IL-1 $\beta, T F$, XOD and $\mathrm{NF}-\kappa \mathrm{B}$ may promote thrombus formation.

\section{Introduction}

Lower extremity deep vein thrombosis (DVT) is a common peripheral vascular disease, which can lead to venous valve insufficiency and concurrent pulmonary embolism (1). The incidence of thrombosis in the left lower extremity is much higher than that in its right counterpart (2), and primary iliac-femoral vein thrombosis is particularly common. DVT of the lower extremity can also extend to the inferior vena cava, or even block the renal vein to cause renal failure and threaten life (3). There are $~ 500,000$ cases of lower extremity DVT in the United States each year. Among them, $10 \%$ of patients develop a fatal pulmonary embolism (4), 20-50\% of patients develop post-thrombotic syndrome (5) and 5-10\% of patients experience severe post-thrombotic syndrome (6).

Previous studies have shown that inflammation plays an important role in the formation of DVT in the lower extremity $(7,8)$. Interleukin-1 $\beta$ (IL-1 $\beta$ ) is an inflammatory cytokine that is a key contributor to the early stage of systemic and local inflammatory reactions and is a marker of an early inflammatory response in the body (9). IL-1 $\beta$ is produced by macrophages and monocytes, and its production can be induced by endotoxin (10). It promotes thrombosis by directly acting on vascular endothelial cells, impairing endothelial function and inducing local thrombosis, and is a major mediator of thrombus formation. IL- $1 \beta$ binds to the IL- $1 \beta$ receptor on endothelial cells and activates the NF- $\kappa$ B pathway to synthesize xanthine dehydrogenase (XD). XD may be converted to xanthine oxidase (XOD), which acts on xanthine and hypoxanthine (HX) to form superoxide anions (11-14). Superoxide anions cause endothelial damage, activate tissue factor (TF), blood clotting and von Willebrand factor and promote platelet adhesion and fibrin deposition, thereby initiating and 
aggravating thrombosis $(15,16)$. However, the mechanism of action by which IL-1 $\beta$ participates in the process of DVT has not yet been fully elucidated.

The DVT model has been widely established in rats $(17,18)$ and is highly reproducible. In this model, thrombosis is induced in deep veins by reducing but not completely blocking the flow of blood. Thus, the blood is in a slow-flowing or stagnant state, leading to thrombosis and mimicking DVT in humans.

In the present study, a DVT model was established in rats. The levels of IL-1 $\beta$, TF, XOD and NF- $\kappa$ B were analyzed. The mechanism of IL-1 $\beta$ in the process of DVT of the lower extremity was further analyzed and evaluated.

\section{Materials and methods}

Animals. A total of 70 male Sprague-Dawley rats (pathogenfree; age, 8-12 weeks; $200 \pm 20 \mathrm{~g}$ body weight) were purchased from the Animal Center of Xinjiang Medical University. The housing conditions of all animals included a room temperature of $20-25^{\circ} \mathrm{C}$, humidity of $50-60 \%, 12 \mathrm{~h}$-light $/ 12 \mathrm{~h}$-dark cycle and free access to food and water. The rats were randomly divided into 7 groups: Control, sham and 5 DVT groups (S2h, S8h, $\mathrm{S} 24 \mathrm{~h}, \mathrm{~S} 48 \mathrm{~h}$ and $\mathrm{S} 72 \mathrm{~h}$ groups). All animal experiments were conducted according to the ethical guidelines of Xinjiang Medical University. The study was approved by the Ethics Committee of Xinjiang Medical University. All efforts were made to minimize animal suffering.

Establishment of the DVT model. The DVT model was established by reducing the blood flow of the rats as previously described (18). A $1.5-\mathrm{cm}$ incision was made along the midline of the abdomen $1 \mathrm{~cm}$ below the xiphoid process. Then, the inferior vena cava was exposed. After separating the vena cava, a 4-0 Ethicon suture was used to ligate the inferior vena cava at a position $1 \mathrm{~cm}$ below the right renal vein. The two collateral veins above the iliac vein were separated and ligated with 5-0 Ethicon suture. The abdominal contents were then returned to the abdominal cavity. After injecting $2-3 \mathrm{ml} 0.9 \%$ sodium chloride, suturing was performed layer by layer. The rats were fed normally. For rats in the sham surgery group, the same procedure was performed but the veins were not ligated. Rats in the control group did not receive any surgical procedure.

Sample collection. Venous tissues, venous thrombus and whole blood were collected from the inferior vena cava of each rat at 2, 8, 24, 48 and $72 \mathrm{~h}$ after DVT modeling surgery in the respective DVT groups, and at 2,8 and $24 \mathrm{~h}$ in the control and sham surgery groups. However, when comparisons were made between the control and sham groups, the data collected at 2 , 8 and $24 \mathrm{~h}$ were not statistically significant. Thus, only one set of data was displayed. Prior to sample collection at each time point, the rats were anesthetized with an intraperitoneal injection of $2 \%$ pentobarbital sodium $(30 \mathrm{mg} / \mathrm{kg})$. Following the induction of anesthesia, the rats were placed in a closed container and euthanized by hypoxia, induced by $\mathrm{CO}_{2}$ at a displacement rate of $30 \%$ container volume $/ \mathrm{min}$. The animals were monitored for breathing and heartbeat. When the breathing and heartbeat stopped, the death of the animals was confirmed. Venous tissues were maintained in liquid nitrogen after washing. Venous thrombus tissues were fixed in $10 \%$ paraformaldehyde at room temperature. Serum was separated from whole blood by centrifugation at $1,000 \mathrm{x}$ g for $15 \mathrm{~min}$ at $4^{\circ} \mathrm{C}$ and kept at $4^{\circ} \mathrm{C}$.

Enzyme-linked immunosorbent assays (ELISAs). The serum levels of IL-1 $\beta$, TF and XOD were detected using ELISAs. Rat pro-IL1 $\beta$ (cat. no. CSB-E08055r; Cusabio Technology, LLC), Rat TF (cat. no. CSB-E07914r; Cusabio Technology, LLC) and Rat XOD ELISA kits (cat. no. CSB-E13614r; Cusabio Technology, LLC) were used. The procedures were conducted according to the protocols provided with the kits. The absorbance value at $450 \mathrm{~nm}$ was read using an $\mathrm{xMark}^{\mathrm{TM}}$ microplate reader (Bio-Rad Laboratories, Inc.).

Flow cytometric analysis. Endothelial cells in the peripheral blood were counted by flow cytometry. In detail, $100 \mu 1$ whole blood was mixed with $65 \mu 110 \%$ formaldehyde and incubated for $30 \mathrm{~min}$ at room temperature in the presence of $0.1 \%$ Triton $^{\mathrm{TM}} \mathrm{X}-100$. After incubation, the cells were washed with PBS and then stained with anti-CD31-FITC monoclonal antibody (cat. no. 11-0319-42; eBioscience) at room temperature for 30-60 min. After washing with PBS, the cells were subjected to flow cytometric analysis on the FACScan flow cytometer (BD Biosciences) equipped with CellQuest ${ }^{\mathrm{TM}}$ software (Version 5.1; BD Biosciences).

Hematoxylin and eosin $(H \& E)$ staining. $\mathrm{H} \& \mathrm{E}$ staining was used to observe the venous thrombotic tissue. The staining was performed according to the protocols provided with the H\&E staining kit (Beijing Solarbio Science \& Technology Co., Ltd.). Briefly, the sections were dewaxed, stained with $\mathrm{H} \& \mathrm{E}$ at room temperature for $3 \mathrm{~min}$, dehydrated, transparentized and mounted. Morphological features were observed under a light microscope (Olympus BX51; Olympus Corporation).

Reverse transcription-quantitative PCR (RT-qPCR). Total RNAs were extracted from the thrombus using an Animal Tissue Total RNA Extraction kit (Tiangen Biotech Co., Ltd.). Subsequently, RNA was reverse transcribed into cDNA with TIANScript II RT Kit (Tiangen Biotech Co., Ltd.). The temperature protocol was as follows: $65^{\circ} \mathrm{C}$ for $5 \mathrm{~min}, 42^{\circ} \mathrm{C}$ for $60 \mathrm{~min}, 85^{\circ} \mathrm{C}$ for $5 \mathrm{~min}$, and $4^{\circ} \mathrm{C}$ for $10 \mathrm{~min}$. qPCR assays were performed using a SuperReal PreMix Plus (SYBR Green; Tiangen Biotech Co., Ltd.) to determine the mRNA levels of $I L-1 \beta, T F, X O D$ and $N F-\kappa B$. The primer sequences used are listed in Table I. GAPDH was used as an internal reference gene. The primers were synthesized by Sangon Biotech Co., Ltd. The qPCR thermocycling conditions were $95^{\circ} \mathrm{C}$ for $1 \mathrm{~min}$ followed by 40 cycles of $95^{\circ} \mathrm{C}$ for $10 \mathrm{sec}$ and $60^{\circ} \mathrm{C}$ for $34 \mathrm{sec}$, and a final extension at $60^{\circ} \mathrm{C}$ for $1 \mathrm{~min}$. The comparative $2^{-\Delta \Delta \mathrm{Cq}}$ method was used for relative quantification (19).

Western blotting. The inferior vena cava tissues were homogenized and lysed for 30 min with RIPA lysis buffer (cat. no. P0013B; Beyotime Institute of Biotechnology). After centrifugation at $29,880 \mathrm{x} \mathrm{g}$ for $5 \mathrm{~min}$ at $4^{\circ} \mathrm{C}$, total proteins were isolated and the protein concentration was quantified using a BCA 200 Protein Quantification kit (Beijing Solarbio Science \& Technology Co., Ltd.). A total of $40 \mu \mathrm{g}$ protein sample/lane was then electrophoresed by $12 \%$ SDS-PAGE 
Table I. Primer sequences.

\begin{tabular}{lll}
\hline Name & Primer & \multicolumn{1}{c}{ Sequence (5'-3') } \\
\hline IL-1 $\beta$ & Forward & CCTGTGTGATGAAAGACGGC \\
& Reverse & TATGTCCCGACCATTGCTGT \\
NF- $\mathrm{kB}$ & Forward & TGACGGGAGGGGAAGAAATC \\
& Reverse & TGAACAAACACGGAAGCTGG \\
TF & Forward & CAAAACGGTCAAATGGTGCG \\
& Reverse & ACCTCCAGAAATGGCCTTGA \\
XOD & Forward & AATGCGGACCCTGAAACAAC \\
& Reverse & TTTCCTATGCCTTCCACGGT \\
\hline
\end{tabular}

IL-1 $\beta$, interleukin- $1 \beta$; TF, tissue factor; XOD, xanthine oxidase.

and transferred to PVDF membranes. The membranes were blocked with $5 \%$ skimmed milk for $1 \mathrm{~h}$ at room temperature and then incubated with primary antibodies against $\mathrm{NF}-\kappa \mathrm{B}$ (1:1,000; cat. no. 10745-1-AP; Proteintech Group, Inc.) and GAPDH (1:5,000; cat. no. 10494-1-AP; Proteintech Group) overnight at $4^{\circ} \mathrm{C}$. After rinsing with TBST (0.1\% Tween-20), the membranes were incubated with the HRP-conjugated secondary antibody (1:10,000; cat. no. BA1054; Boster Biological Technology, Ltd.) for $1 \mathrm{~h}$ at room temperature. Finally, an ECL kit (Pierce ${ }^{\mathrm{TM}}$ Fast Western Blot kit; Thermo Fisher Scientific, Inc.) was used for visualization of the protein bands. The densities of the bands were measured using Quantity-one software (version 4.6.6; Bio-Rad Laboratories, Inc.). The gray ratio of $\mathrm{NF}-\kappa \mathrm{B}$ to GAPDH was used to determine the relative expression level of $\mathrm{NF}-\kappa \mathrm{B}$.

Statistical analysis. All assays were performed three times to ensure reproducibility. All results are expressed as the mean \pm SD and statistical analysis was performed using SPSS statistical software (version 13.0; SPSS, Inc.). One-way ANOVA was used to compare differences among groups followed by Tukey's test for pairwise comparisons. $\mathrm{P}<0.05$ was considered to indicate a statistically significant difference.

\section{Results}

Comparison of IL-1 $\beta, T F$ and XOD levels in serum. The levels of IL-1 $\beta$, TF and XOD in the serum were determined using ELISAs. The levels of IL-1 $\beta$, TF and XOD in the rats with inferior venous thrombosis exhibited an increasing trend from 2 to $24 \mathrm{~h}$, reaching a peak at $24 \mathrm{~h}$ and then gradually decreasing from 48 to $72 \mathrm{~h}$ (Fig. 1). As shown in Fig. 1A, the levels of IL-1 $\beta$ in the S8h, S24h and S48h inferior venous thrombosis groups were significantly higher compared with those in the control and sham surgery groups $(\mathrm{P}<0.05)$. As shown in Fig. $1 \mathrm{~B}$, the levels of TF in the S8h and S24h inferior venous thrombosis groups were significantly higher compared with those in the control and sham surgery groups $(\mathrm{P}<0.05)$. However, the $\mathrm{S} 48 \mathrm{~h}$ and $\mathrm{S} 72 \mathrm{~h}$ inferior venous thrombosis groups exhibited no difference in TF levels compared with those in the control and sham surgery groups. As shown in Fig. 1C, the level of XOD in the S24h inferior venous thrombosis group was significantly higher compared with those in the control and sham surgery groups
$(\mathrm{P}<0.05)$, while the $\mathrm{S} 2 \mathrm{~h}, \mathrm{~S} 8 \mathrm{~h}$ and $\mathrm{S} 48 \mathrm{~h}$ inferior venous stenosis groups exhibited no difference in XOD levels compared with those in the control and sham surgery groups. Furthermore, no significant differences between the control and sham surgery groups were detected. These results show that DVT of the lower extremities induced changes in the serum levels of IL-1 $\beta$, TF and XOD. The levels of the three indicator proteins peaked at $24 \mathrm{~h}$ in the DVT groups, and exhibited statistically significant differences compared with the control and sham surgery groups, indicating that the inflammatory factor IL-1 $\beta$ and the associated markers TF and XOD may promote thrombosis.

Histopathological changes of venous thrombosis. To analyze the morphological changes associated with venous thrombosis, H\&E staining was performed. The staining revealed that in the control group, the surface of the intima was smooth, the endothelial cells were evenly arranged and no thrombus was present (Fig. 2). However, at $2 \mathrm{~h}$ after surgery, thrombus filled the venous lumen, no granulation tissue was visible in the thrombus, and no adhesion of the thrombus to the vascular wall was observed. In addition, a few vascular endothelial cells were detached and inflammatory cells infiltrated around the vein; there were numerous red blood cells but few infiltrative inflammatory cells (Fig. 2). At 8 h, no adhesion between the thrombus and vascular wall was evident. In addition, fibroblasts were observed at the margin of the thrombus, the number of neutrophils was markedly increased, a small number of endothelial cells were detached from the valve and the number of surrounding inflammatory cells was increased (Fig. 2). At $48 \mathrm{~h}$ after the DVT modeling surgery, granulation tissue was clearly observed, the thrombus was partially adherent to the vessel wall, and the infiltration of inflammatory cells around the vein was evident. In addition, the endothelium was detached from the valve and the valve was damaged (Fig. 2). At $72 \mathrm{~h}$ after the surgery, a large amount of granulation tissue was present, and adhesion between the thrombus and vessel wall was apparent. In addition, inflammatory cells had infiltrated around the vein and the structure of the valve was destroyed (Fig. 2). These results demonstrate the changes associated with the formation of DVT in the lower extremities at different time points.

Changes in the number of circulating endothelial cells (CECS) in the peripheral blood. To analyze the relationship between the number of endothelial cells in the peripheral blood circulation and thrombosis, the flow cytometric analysis of CD31-FITC-H was performed in the 7 groups of rats. As shown in Fig. 3, the level of CD31 positivity in the blood of rats with inferior venous stenosis exhibited an upward trend from 8 to $72 \mathrm{~h}$. The levels of CD31 in the S2h and S8h inferior venous stenosis groups exhibited no significant differences compared with those in the control and sham surgery groups. However, the CD31 levels in the S24h, S48h and S72h inferior venous stenosis groups were significantly higher compared with those in the control and sham surgery groups $(\mathrm{P}<0.05)$. In addition, the level of CD31 exhibited significant differences among the 24,48 and $72 \mathrm{~h}$ inferior venous stenosis groups $(\mathrm{P}<0.05)$, but no significant difference was observed between the control and sham surgery groups. These results indicate that the degree of venous endothelial cell damage is associated with the number of CECs in the peripheral blood. 

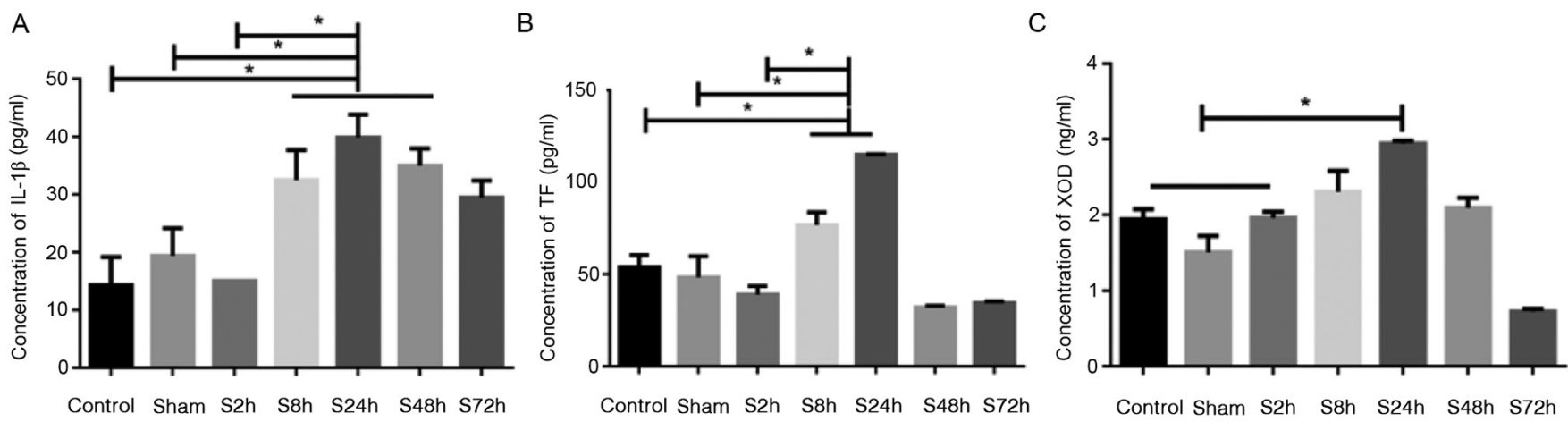

Figure 1. Comparison of IL-1 $\beta, T F$ and XOD levels in serum. Rats were randomly divided into 7 groups: Control, sham and 5 DVT groups, namely S2h, S8h, S24h, S48h and S72h, which were examined 2, 8, 24, 48 and $72 \mathrm{~h}$ after DVT modeling surgery, respectively. ELISAs were used to analyze the levels of (A) IL-1 $\beta$, (B) TF and (C) XOD in the serum. "P<0.05 as indicated. IL-1 $\beta$, interleukin- $1 \beta$; TF, tissue factor; XOD, xanthine oxidase; DVT, deep vein thrombosis.
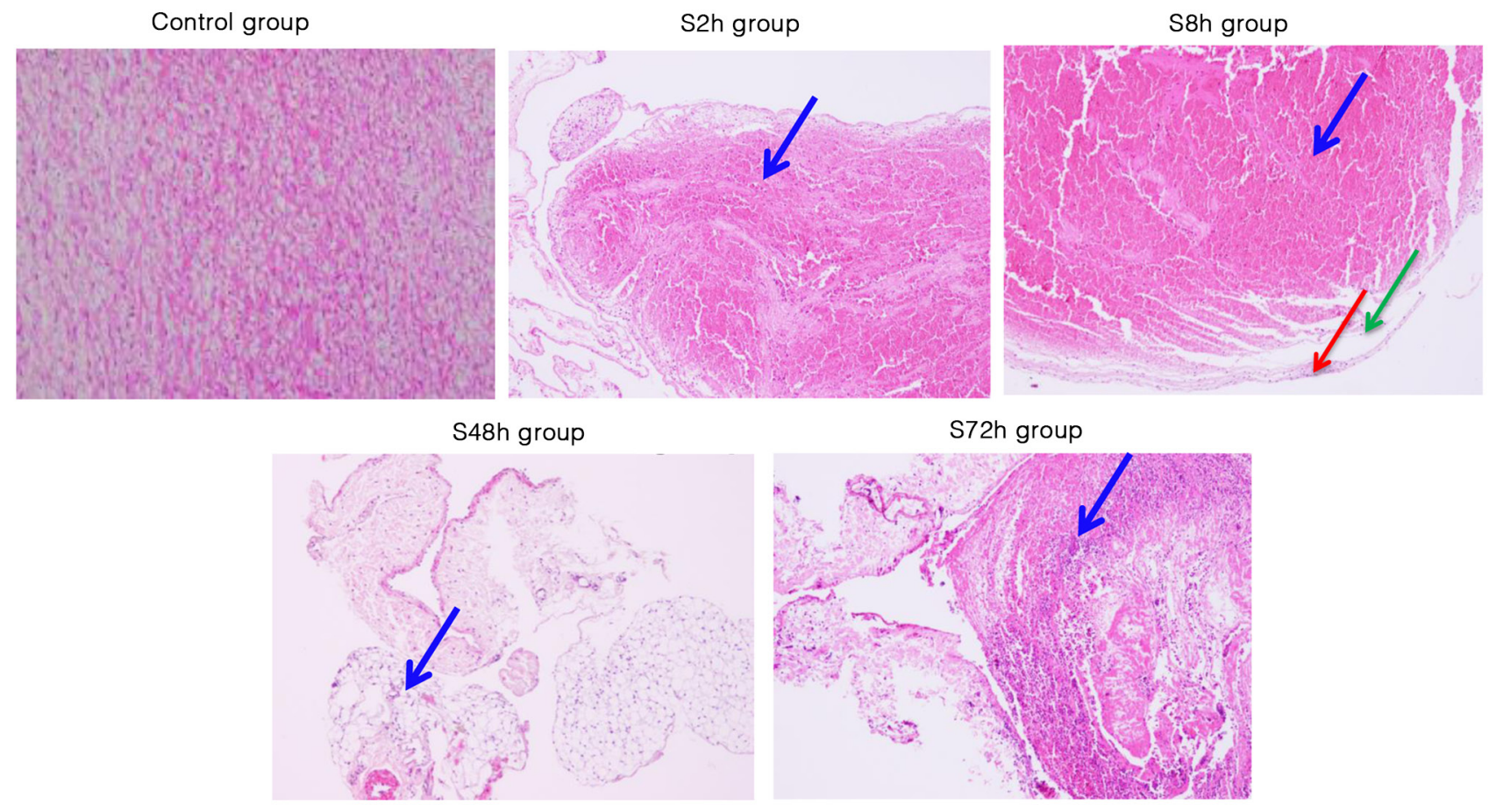

Figure 2. Histopathological changes associated with venous thrombosis revealed by hematoxylin and eosin staining. Representative images of inferior vena cava from the control and S2h, S8h, S48h and S72h deep vein thrombosis groups are shown. Blue arrows indicate thrombus, the red arrow indicates neutrophils and the green arrow indicates fibroblasts. Magnification, x100 under a light microscope.

Differential expression of $I L-1 \beta, T F, X O D$ and $N F-\kappa B$ mRNA. RT-qPCR was used to detect the mRNA levels of $I L-1 \beta, T F$, $X O D$ and $N F-\kappa B$ in the control, sham surgery and inferior venous stenosis groups. The mRNA levels of $I L-1 \beta$ (Fig. 4A), $N F$ - $K B$ (Fig. 4B), $T F$ (Fig. 4C) and XOD (Fig. 4D) exhibited no significant differences between the control and sham surgery groups. However, the levels of these mRNAs in the S24h inferior venous stenosis group were significantly higher compared with those in the control and sham surgery groups $(\mathrm{P}<0.05)$. These results demonstrate that $I L-1 \beta, N F-\kappa B, T F$ and $X O D$ mRNA expression levels were elevated in the thrombus tissues of the DVT model rats.

Differences in $N F-\kappa B$ protein expression in tissues. The protein expression levels of NF-kB in the venous tissues of the control, sham surgery and inferior venous stenosis groups were detected by western blotting (Fig. 5). The protein expression of NF- $\kappa B$ exhibited no significant difference between the control and sham surgery groups; however, NF- $\mathrm{kB}$ expression levels in the 2-72 $\mathrm{h}$ inferior venous stenosis groups were significantly higher compared with those in the control and sham surgery groups $(\mathrm{P}<0.05)$. These results indicate that the expression of $\mathrm{NF}-\kappa \mathrm{B}$ is elevated in the venous tissues of DVT model rats.

\section{Discussion}

CD31, also known as platelet/endothelial cell adhesion molecule 1 , is a transmembrane glycoprotein with a molecular mass of $130 \mathrm{kDa}$. It is expressed at high levels at the junctions of vascular endothelial cells and is a member of the immunoglobulin superfamily. CD31 promotes platelet adhesion and thrombosis (20) and is mainly expressed on the surface of 

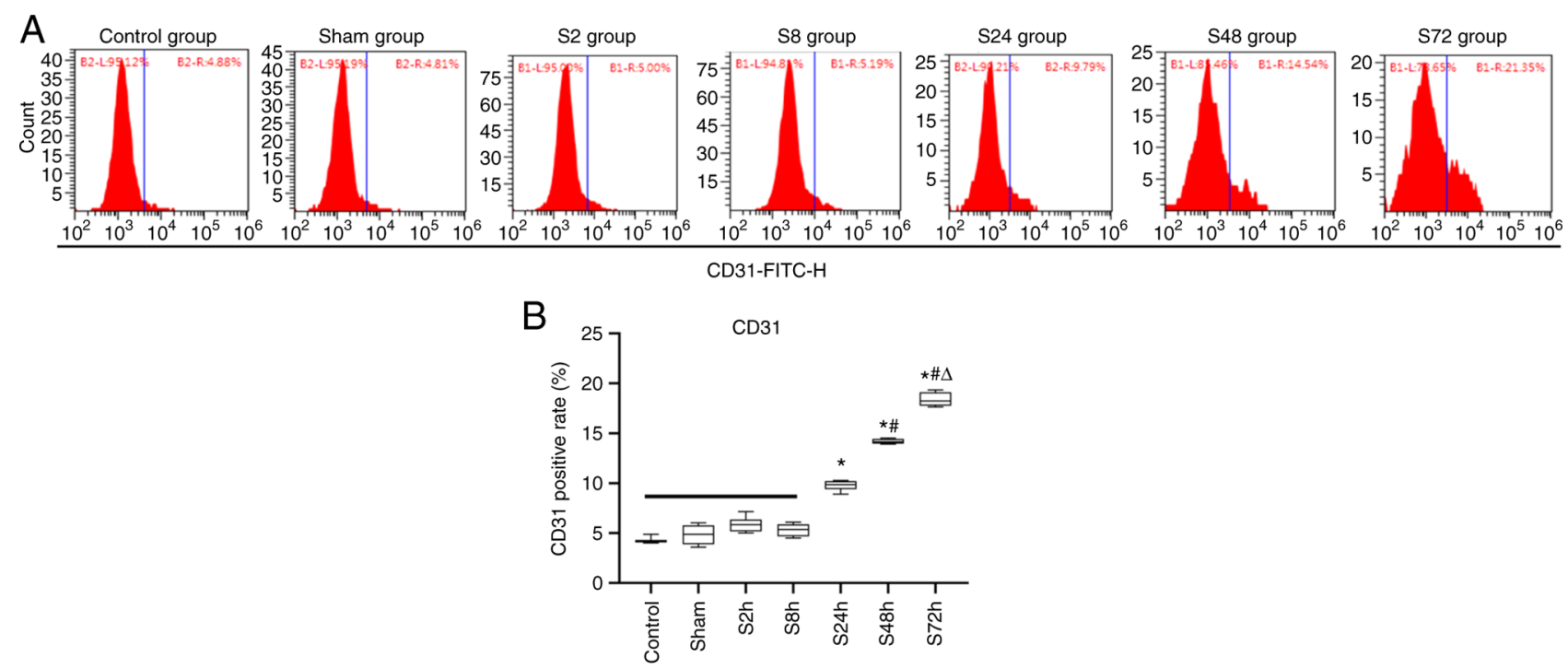

Figure 3. Changes in the expression rate of CD31 in the peripheral blood of rats. Rats were randomly divided into the control, sham surgery and S2h, S8h, S24h, S48h and S72h groups, which were examined 2, 8, 24, 48 and $72 \mathrm{~h}$ after deep vein thrombosis modeling surgery, respectively. Flow cytometry was used to analyze the positive rate of the peripheral blood endothelial cell marker CD31. (A) Representative flow cytometry plots for each group. (B) Statistical analysis of the CD31 positive rate in each group. ${ }^{*} \mathrm{P}<0.05$ vs. Control, sham, 2 , and $8 \mathrm{~h}$ groups; ${ }^{~} \mathrm{P}<0.05$ vs. $24 \mathrm{~h}$ group; ${ }^{\wedge} \mathrm{P}<0.05$ vs. $48 \mathrm{~h}$ group.

A

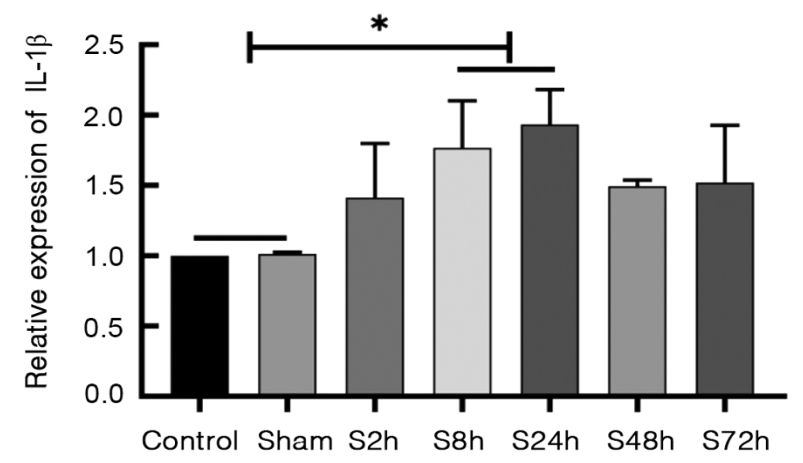

C

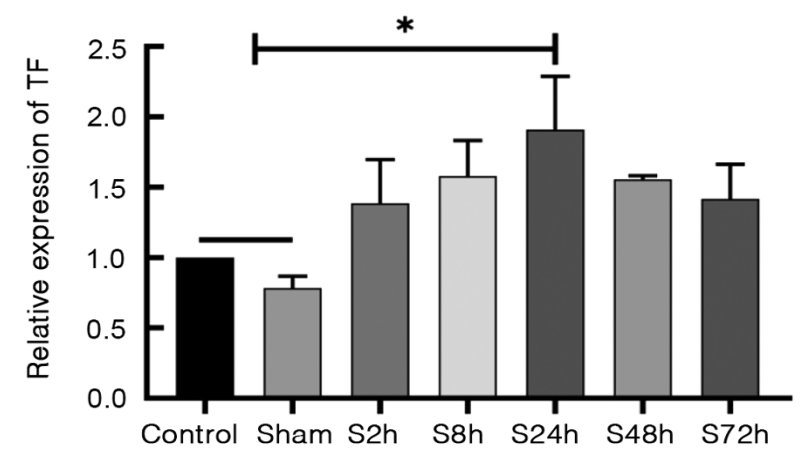

B

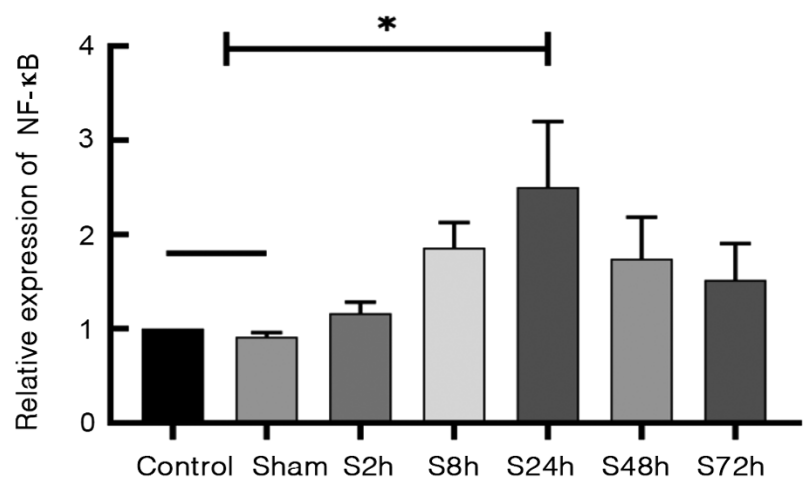

D

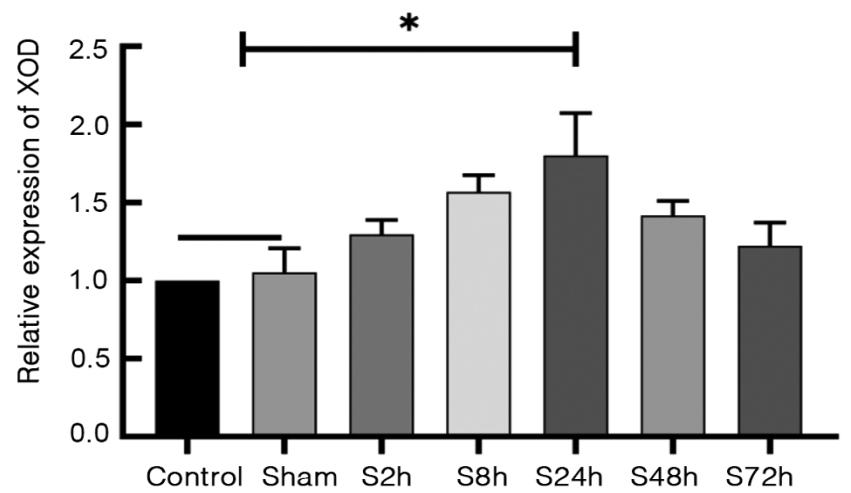

Figure 4. Expression of $I L-1 \beta, T F, X O D$ and $N F-\kappa B$ mRNA. Rats were randomly divided into the control, sham surgery and S2h, S8h, S24h, S48h and S72h groups, which were examined 2, 8, 24, 48 and $72 \mathrm{~h}$ after deep vein thrombosis modeling surgery, respectively. Reverse transcription-quantitative PCR was used to detect the mRNA levels in thrombus tissues. The mRNA levels of (A) $I L-1 \beta$, (B) $N F-\kappa B$, (C) $T F$ and (D) $X O D$ are shown. ${ }^{*} \mathrm{P}<0.05$ as indicated. IL-1 $\beta$, interleukin-1 $\beta$; TF, tissue factor; XOD, xanthine oxidase.

cells such as endothelial cells, platelets and monocytes (21). It is used as a specific marker of vascular endothelial cells. In the present study, flow cytometric analysis revealed that the expression level of CD31 was increased in rats with inferior venous stenosis and increased significantly from 8 to $72 \mathrm{~h}$ after DVT surgery.

CECs are present in peripheral blood following vascular endothelium damage. The number of CECs is closely 
Control Sham S2h S8h S24h S48h S72h

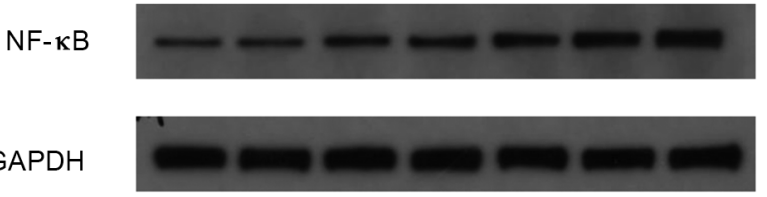

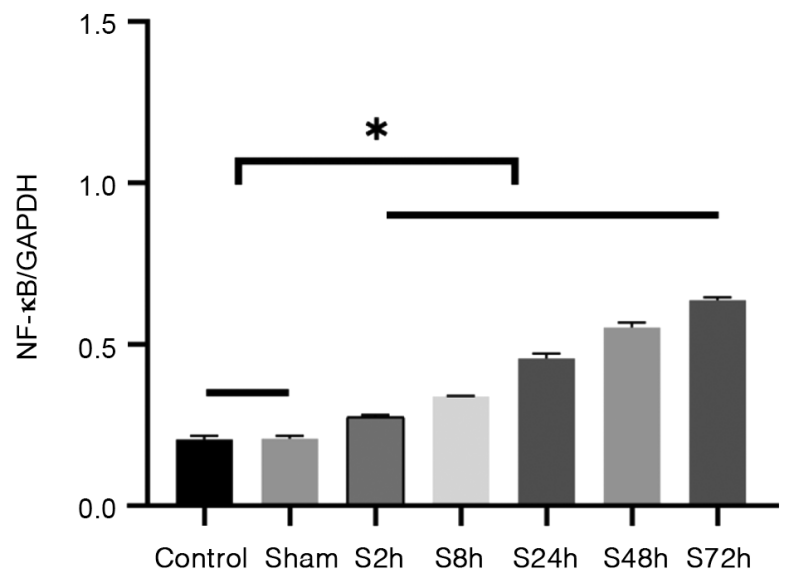

Figure 5. Expression of NF-кB protein in venous tissues. Rats were randomly divided into the control, sham surgery and S2h, S8h, S24h, S48h and S72h groups, which were examined 2, 8, 24, 48 and $72 \mathrm{~h}$ after deep vein thrombosis modeling surgery, respectively. Western blotting was used to detect the NF- $\mathrm{B}$ protein levels in each group. Representative western blots and quantitative results are shown in the left and right panels, respectively. ${ }^{*} \mathrm{P}<0.05$ as indicated.

associated with the degree of vascular endothelial injury; therefore, it can be used as an index to evaluate the degree of vascular injury (22). In the present study, flow cytometry indicated that the number of CECs in the peripheral blood of the rats 24-72 $\mathrm{h}$ following the induction of DVT was significantly higher than that of rats in the control group. In addition, the expression levels of NF- $\kappa \mathrm{B}$ and IL-1 $\beta$ were positively associated with the number of CECs in the peripheral blood. These findings indicate that inflammation occurred in the rats with inferior venous stenosis due to endothelial cell damage, and the high expression of IL- $1 \beta$ causes oxidative stress and may promote thrombus formation.

IL-1 $\beta$ is an inflammatory cytokine that plays an important role in the early stages of systemic and local inflammatory reactions, and is a marker of early inflammatory response in the body (9). IL-1 $\beta$ is generated by macrophages and monocytes and its production may be induced by endotoxin (10). It acts directly on vascular endothelial cells, where it impairs endothelial function and promotes local thrombosis (23). Therefore, IL-1 $\beta$ is important in thrombus formation. The present study demonstrated that the levels of IL-1 $\beta$ in the peripheral blood and tissues of DVT model rats were higher than those in the control and sham surgery groups. As the severity of the thrombus increased, the level of IL-1 $\beta$ also increased, suggesting that IL-1 $\beta$ may be involved in thrombus formation. Therefore, IL-1 $\beta$ may be used as an indicator to judge the occurrence and severity of DVT.

$\mathrm{XOD}$ is a molybdenum-containing flavin protease present in various organisms $(24,25)$, which can catalyze the conversion of HX to xanthine. XOD is derived from XD by the oxidation of cysteine residues; when activated XOD produces superoxide radicals that induce oxidative damage (26), directly activate the inflammatory signaling cascade and promote an immune response. Oxidative stress-mediated damage primarily promotes an inflammatory response by upregulating the expression of pro-inflammatory cytokines (27). The present study showed that the levels of IL-1 $\beta$ in the peripheral blood and tissues of the DVT model rats were positively associated with those of XOD. As the severity of the thrombus increased, the level of IL-1 $\beta$ increased gradually and the level of XOD also increased, suggesting that IL-1 $\beta$ promotes the expression of XOD and exacerbates tissue damage.

$\mathrm{TF}$ is the only transmembrane glycoprotein expressed on cell surfaces in the coagulation system and it initiates major exogenous coagulation pathways in the body $(28,29)$. When blood vessels are damaged, endothelial cells and damaged vascular endothelial fibroblasts express TF to initiate the coagulation process (30). Inflammation is an important component of thrombotic diseases. Inflammatory responses induce endothelial cells and monocytes to express TF, synthesize and release various adhesion molecules, inflammatory mediators and chemokines, expand the inflammatory response and promote thrombosis (31). The present study demonstrated that the expression levels of TF in the peripheral blood and tissues of the rat model of DVT were significantly increased compared with those in sham surgery and control groups, suggesting that TF participates in the thrombosis formation process, and is positively associated with IL-1 $\beta$. IL- $1 \beta$ possibly promotes thrombosis by inducing the expression of TF.

When cells are stimulated by ischemia, hypoxia, viral microbes, cytokines and inflammation, NF- $\kappa \mathrm{B}$ dissociates from $\mathrm{I} \kappa \mathrm{B}$ and enters the nucleus where it regulates gene expression (32). The effect of activated NF- $\kappa \mathrm{B}$ on cells is manifested by the inhibition of apoptosis or promotion of the expression of inflammation-associated proteins (33). The present study revealed that $\mathrm{NF}-\kappa \mathrm{B}$ was only weakly expressed in the control and sham surgery groups. However, NF- $\kappa \mathrm{B}$ expression in the venous blood vessels was significantly increased after DVT; the expression of $N F-\kappa B$ mRNA began to increase at $2 \mathrm{~h}$ after surgery, peaked at $24 \mathrm{~h}$ and then gradually decreased while the expression of $\mathrm{NF}-\kappa \mathrm{B}$ exhibited an increasing trend from 2 to $72 \mathrm{~h}$. This indicates that NF- $\mathrm{BB}$ is closely associated with thrombosis.

Inflammation and thrombosis are associated by an intricate network in the body (34-36). Inflammatory factors can promote the secretion of blood coagulation factors, making the blood hypercoagulable and more likely to form a thrombus. Furthermore, initiation of the coagulation cascade can induce the release of inflammatory factors, aggravating inflammation (37-39). The present study indicated that the high expression of IL-1 $\beta$ in the DVT model is positively associated 
with the expression of TF, XOD and NF- $\kappa \mathrm{B}$, and closely associated with the extent of the endothelial cell damage, which together promote thrombosis.

In conclusion, the present study suggests that IL- $1 \beta, \mathrm{TF}$, XOD and NF- $\mathrm{KB}$ play important roles in the development of DVT. These findings may provide a theoretical basis for the clinical diagnosis and treatment of DVT by suggesting relevant indices for detection.

\section{Acknowledgements}

Not applicable.

\section{Funding}

No funding was received.

\section{Availability of data and materials}

All data generated or analyzed during this study are included in this published article.

\section{Authors' contributions}

XG designed the study. RZP and QF collected the data. RZP, QF and GT performed the statistical analysis. RZP and $\mathrm{XG}$ interpreted the data. RZP prepared the manuscript. BZ performed H\&E staining. RZP, QF and GT confirm the authenticity of all the raw data. All authors read and approved the final manuscript.

\section{Ethics approval and consent to participate}

The animal experiments were approved by the Ethics Committee of Xinjiang Medical University and conducted according to the ethical guidelines of Xinjiang Medical University. All efforts were made to minimize animal suffering.

\section{Patient consent for publication}

Not applicable.

\section{Competing interests}

All authors declare that they have no competing interests.

\section{References}

1. Crop MJ, Siemes C, Berendes P, van der Straaten F, Willemsen S and Levin MD: Influence of C-reactive protein levels and age on the value of D-dimer in diagnosing pulmonary embolism. Eur J Haematol 92: 147-155, 2014.

2. Ibrahim NA, Hassan FM, Elgari MM and Abdalla SE: Risk factors for deep vein thrombosis of lower extremities in sudanese women. Vasc Health Risk Manag 14: 157-164, 2018.

3. Li Y, Wei WF, Lin SM,Liu ZJ, Huang HC and Qiu WL: Expression of inflammatory factors in pregnant women with acute venous thrombosis and its relationship with the degree of vascular injury. Guangdong Med J 35: 558-560, 2014 (In Chinese).

4. Alexander P and Giangola G: Deep venous thrombosis and pulmonary embolism: Diagnosis, prophylaxis, and treatment. Ann Vasc Surg 13: 318-327, 1999.
5. Kahn SR, Shrier I, Julian JA, Ducruet T, Arsenault L, Miron MJ, Roussin A, Desmarais S, Joyal F, Kassis J, et al: Determinants and time course of the postthrombotic syndrome after acute deep venous thrombosis. Ann Intern Med 149: 698-707, 2008

6. Kahn SR: The post thrombotic syndrome. Thromb Res 127 (Suppl 3): S89-S92, 2011.

7. Zhang T, Li Q, Wang L and Li G: Expression variations and clinical significance of MMP-1, MMP-2 and inflammatory factors in serum of patients with deep venous thrombosis of lower extremity. Exp Ther Med 17: 181-186, 2019.

8. Zhou J, Pang L, Zuo B and Yan B: Discussion on the clinical application of deep vein thrombosis risk assessment module. Attend Pract and Res 11: 117-118, 2015 (In Chinese).

9. Torbicki A, Perrier A, Konstantinides S, Agnelli G, Galiè N, Pruszczyk P, Bengel F, Brady AJ, Ferreira D, Janssens U, et al: Guidelines on the diagnosis and management of acute pulmonary embolism: The task force for the diagnosis and management of acute pulmonary embolism of the European society of cardiology (ESC). Eur Heart J 29: 2276-2315, 2008.

10. Goekoop RJ, Steeghs N, Niessen RW, Jonkers GJ, Dik H, Castel A, Gelder LW, Vlasveld LT, van Klink RC, Planken EV and Huisman MV: Simple and safe exclusion of pulmonary embolism in outpatients using quantitative D-dimer and wells simplified decision rule. Thromb Haemostasis 97: 146-150, 2007.

11. Deem TL and Cook-Mills JM: Vascular cell adhesion molecule 1 (VCAM-1) activation of endothelial cell matrix metalloproteinases: Role of reactive oxygen species. Blood 104: 2385-2393, 2004.

12. Erusalimsky JD: Vascular endothelial senescence: From mechanisms to pathophysiology. J Appl Physiol (1985) 106: 326-332, 2009.

13. Fan LM, Douglas G, Bendall JK, McNeill E, Crabtree MJ, Hale AB, Mai A, Li JM, McAteer MA, Schneider JE, et al: Endothelial cell-specific reactive oxygen species production increases susceptibility to aortic dissection. Circulation 129: 2661-2672, 2014

14. Wakefield TW, Myers DD and Henke PK: Mechanisms of venous thrombosis and resolution. Arterioscler Thromb Vasc Biol 28: 387-391, 2008.

15. Kanaji N, Sato T, Nelson A, Wang X, Li Y, Kim M, Nakanishi M, Basma H, Michalski J, Farid M, et al: Inflammatory cytokines regulate endothelial cell survival and tissue repair functions via NF- $\kappa$ B signaling. J Inflam Res 4: 127-138, 2011.

16. Phan SH, Gannon DE, Varani J, Ryan US and Ward PA: Xanthine oxidase activity in rat pulmonary artery endothelial cells and its alteration by activated neutrophils. Am J Pathol 134: 1201-1211, 1989.

17. Ma J, Li X, Wang Y, Yang Z and Luo J: Rivaroxaban attenuates thrombosis by targeting the NF- $\kappa \mathrm{B}$ signaling pathway in a rat model of deep venous thrombus. Int J Mol Med 40: 1869-1880, 2017.

18. Humphries J, Gossage JA, Modarai B, Burnand KG, Sisson TH, Murdoch C and Smith A: Monocyte urokinase-type plasminogen activator up-regulation reduces thrombus size in a model of venous thrombosis. J Vasc Surg 50: 1127-1134, 2009.

19. Livak KJ and Schmittgen TD: Analysis of relative gene expression data using real-time quantitative PCR and the 2(-Delta Delta $\mathrm{C}(\mathrm{T})$ ) method. Methods 25: 402-408, 2001.

20. Feng YM, Chen XH and Zhang X: Roles of PECAM-1 in cell function and disease progression. Eur Rev Med Pharmacol Sci 20: 4082-4088, 2016.

21. Woodfin A, Voisin MB and Nourshargh S: PECAM-1: A multi-functional molecule in inflammation and vascular biology. Arterioscler Thromb Vasc Biol 27: 2514-2523, 2007.

22. Tuzcu ZB, Asicioglu E, Sunbul M, Ozben B, Arikan H and Koc M: Circulating endothelial cell number and markers of endothelial dysfunction in previously preeclamptic women. Am J Obstet Gynecol 213: 533, 2015.

23. van de Veerdonk FL and Netea MG: New insights in the immunobiology of IL-1 family members. Front Immunol 4: 167, 2013.

24. Moriwaki Y, Yamamoto T and Higashino K: Distribution and pathophysiologic role of molybdenum-containing enzymes. Histol Histopathol 12: 513-524, 1997.

25. Zeki S, Miura S, Suzuki H, Watanabe N, Adachi M, Yokoyama H, Horie Y, Saito H, Kato S and Ishii H: Xanthine oxidase-derived oxygen radicals play significant roles in the development of chronic pancreatitis in WBN/Kob rats. J Gastroenterol Hepatol 17: 606-616, 2002.

26. Lassegue B, Martin AS and Griendling KK: Biochemistry, physiology, and pathophysiology of NADPH oxidases in the cardiovascular system. Circ Res 110: 1364-1390, 2012. 
27. Nomura J, Busso N, Ives A, Matsui C, Tsujimoto S, Shirakura T, Tamura M, Kobayashi T, So A and Yamanaka Y: Xanthine oxidase inhibition by febuxostat attenuates experimental atherosclerosis in mice. Sci Rep 4: 4554, 2014.

28. Breitenstein A, Tanner FC and Luscher TF: Tissue factor and cardiovascular disease: Quo vadis? Circ J 74: 3-12, 2010.

29. Yao XJ, Zhao ZM and Xia T: Inflammation and Thrombosis Chinese J Thromb Hemostasis 21: 190-192, 2015 (In Chinese).

30. Lopez-Vilchez I, Galan AM, Hernandez MR, Caballo C, Roque M, Diaz-Ricart M, White JG and Escolar G: Platelet-associated tissue factor enhances platelet reactivity and thrombin generation in experimental studies in vitro. Thromb Res 130: e294-e300, 2012.

31. Li J and Yan W: Relationship between neutrophil activation and pathological progression of venous thrombosis. Chinese J Trad Med Traumatology Orthopedics 17: 70-72, 2009 (In Chinese).

32. Lawrence T: The nuclear factor NF-kappaB pathway in inflammation. Cold Spring Harb Perspect Biol 1: a001651, 2009.

33. Beg AA and Baldimore D: An essential role for NF-kappaB in preventing TNF-alpha-induced cell death. Science 274: 782-784, 1996.

34. Blix K, Jensvoll H, Brækkan SK and Hansen JB: White blood cell count measured prior to cancer development is associated with future risk of venous thromboembolism-the troms $\varnothing$ study. PLoS One 8: e73447, 2013.
35. Boyle S, White RH, Brunson A and Wun T: Splenectomy and the incidence of venous thromboembolism and sepsis in patients with immune thrombocytopenia. Blood 121: 4782-4790, 2013.

36. Malgor RD and Labropoulos N: Re-modelling of venous thrombosis. Phlebology 28 (Suppl 1): S25-S28, 2013.

37. Deatrick KB, Obi A,LukeCE,Elfline MA, Sood V,Upchurch GR Jr, Jaffer F, Wakefield TW and Henke PK: Matrix metalloproteinase-9 deletion is associated with decreased mid-term vein wall fibrosis in experimental stasis DVT. Thromb Res 132: 360-366, 2013.

38. Ripplinger CM, Kessinger CW, Li C, Kim JW, McCarthy JR, Weissleder R, Henke PK, Lin CP and Jaffer FA: Inflammation modulates murine venous thrombosis resolution in vivo: Assessment by multimodal fluorescence molecular imaging. Arterioscler Thromb Vasc Biol 32: 2616-2624, 2012.

39. Rodriguez AL, Wojcik BM, Wrobleski SK, Myers DD Jr, Wakefield TW and Diaz JA: Statins, inflammation and deep vein thrombosis: A systematic review. J Thromb Thrombolysis 33: 371-382, 2012.

This work is licensed under a Creative Commons Attribution-NonCommercial-NoDerivatives 4.0 International (CC BY-NC-ND 4.0) License. 